\title{
RESEARCH IN SURFACE ROUGHNESS FOR LASER CLADDING COATINGS
}

\author{
Natalija Bulaha ${ }^{1}$, Sergejs Locs ${ }^{1,2}$ \\ ${ }^{1}$ Riga Technical University, Latvia; ${ }^{2}$ Daugavpils University, Latvia \\ natalija.bulaha@rtu.lv, sergey.loch@gmail.com
}

\begin{abstract}
In the present research the laser cladding process, as one of the most effective ways to improve surface characteristics, namely corrosion resistance, wear resistance, heat resistance etc., was investigated. Samples with high-speed tool steel coatings, cladded on spring steel substrate by the laser cladding method using different cladding regimes and cladding directions have been analysed. For this reason the main goal was to find the relation between the direction of flat grinding of the coatings and the direction of laser cladding in cases when the sample has been grinded in a parallel way to the cladded beads and perpendicularly to them. For the roughness analysis of laser cladding coatings the modern 3D measuring system Taylor Hobson Talysurf Intra 50 has been used, by the help of which 3D and 2D surface roughness parameters were determined. When comparing the roughness parameters of both sample series separately it was found that laser cladding regimes, particularly laser focus, have influence on the surface roughness spacing parameters and correlation of the surface ordinates, what is of importance for friction and wear calculations. Whereas by comparing the sample surfaces grinded perpendicularly to the cladding direction and parallel to it, it was discovered that the values of roughness parameters did not differ essentially, pointing to the fact that the mechanical treatment direction towards the direction of laser scanning does not affect surface roughness.
\end{abstract}

Keywords: laser cladding, coating, 3D roughness, high-speed tool steel, regression analysis.

\section{Introduction}

Nowadays, a lot of researches are carried out related to the surface quality improvement of a part, especially to increasing of wear resistance. As it is well known, usage of press moulds, stamping tools, casting forms, shafts and other machinery elements usually comes with the processes of surface wear, which significantly affects the life time of an operational unit. Laser cladding is one of the most effective ways to improve the surface characteristics, namely corrosion resistance, wear resistance, heat resistance etc. Furthermore, the material can be cladded on worn out surfaces in cases of repair or as a protective coating on new parts [1].

However, by laser cladding not only the mechanical characteristics of the cladded material are of importance but also cladding roughness after machining, which also strongly affects the surface wear resistance while in contact. Surface roughness parameters have influence on exploitation characteristics of machine parts. Therefore, in order to ensure certain roughness parameters it is necessary to carry out the laser cladding technology analysis for the purpose of getting understanding how the cladding regimes affect surface roughness [2].

\section{Materials and methods}

The experimental coatings were created using the laser cladding (LC) process. The applied LC system (Fig. 2) consists of industrial 6 axis robot KR30HA and 2 axis DKP-400 positioner (Kuka) and a $100 \mu \mathrm{m}$ ytterbium fiber laser YLR 1000 (IPG Laser), which emits the light beam with a wavelength of $1070 \mathrm{~nm}$. Laser with variable power up to $1000 \mathrm{~W}$ was integrated to the coaxial powder supplying cladding head with the optical system WT03 (Permanova Laser system). Powder mass feeding was performed with the powder feeder TWIN-10-C (Sulzer Metco), where argon was used as a carrier gas and as a shielding gas as well.

Laser cladding experiments were performed on high carbon wear resistant steel (spring steel) DIN 66Mn4 samples with dimensions of 100x100x10 mm. The plates were grinded before treatment. Globe-shape high-speed tool steel powder AISI M2 was used to produce the coatings.

With the aim to establish the influence of three LC process parameters (overlap ratio, scanning speed and laser beam focus distance) onto surface roughness of the coatings after post-processing (grinding) the experiments were carried out against planned two level full factorial design $2^{3}$ (Table 1). 


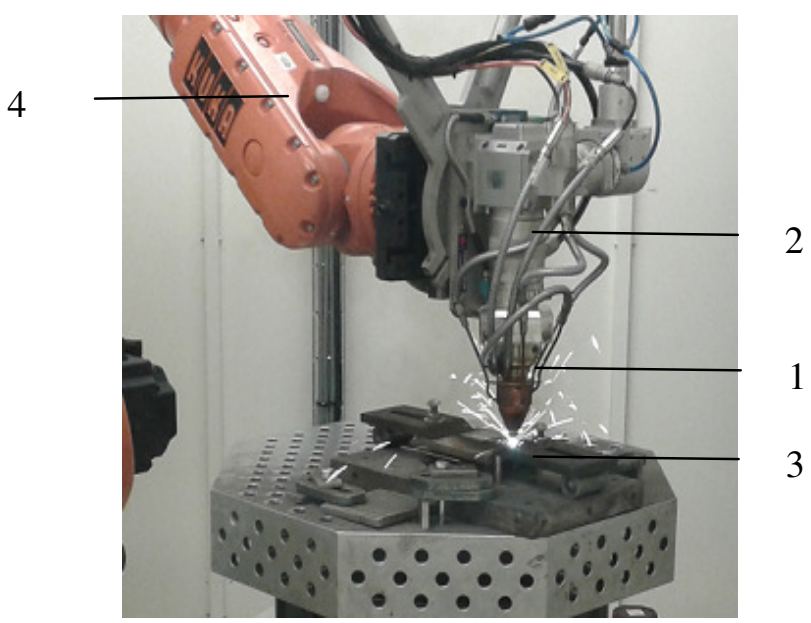

Fig. 1. Laser cladding equipment: 1 - experimental sample; 2 - coaxial laser cladding head; 3 - table of positioner; 4 - industrial robot.

The coatings were created by successive scanning of the surface at various combinations of the parameters. While the processing laser beam was directed to the surface of the sample, i.e. stand-off distance $8 \mathrm{~mm}$ from the nozzle end. The following process parameters were fixed to operate: laser power $1000 \mathrm{~W}$; carrier gas flow (Ar) $51 \cdot \mathrm{min}^{-1}$; shielding gas flow (Ar) $161 \cdot \mathrm{min}^{-1}$, powder mass feed rate $7 \mathrm{~g} \cdot \mathrm{min}^{-1}$. Overall 16 coatings were deposited (with area $45 \times 45 \mathrm{~mm}$ for each coating), which were performed by successive partly overlapping single cladding tracks.

Table 1

\section{Experimental design matrix}

\begin{tabular}{|c|c|c|c|}
\hline Sample No. & OR, $\%$ & Speed, $\mathbf{~ m}^{\cdot \mathbf{1}}$ & Focus, $\mathbf{~ m m ~}$ \\
\hline 1-PP, 1-PD & 50 & 0.02 & -2 \\
\hline 2-PP, 2-PD & 35 & 0.02 & -2 \\
\hline 3-PP, 3-PD & 50 & 0.01 & -2 \\
\hline 4-PP, 4-PD & 35 & 0.01 & -2 \\
\hline 5-PP, 5-PD & 50 & 0.02 & 2 \\
\hline 6-PP, 6-PD & 35 & 0.02 & 2 \\
\hline 7-PP, 7-PD & 50 & 0.01 & 2 \\
\hline 8-PP, 8-PD & 35 & 0.01 & 2 \\
\hline
\end{tabular}

Fig. 2 shows the laser coatings for some samples after the laser cladding experiments. At once it can be observed that depending on the regime combination the distance between the cladded beads and their width has been changing. However, to check whether this feature will affect the surface quality after machining, flat grinding experiments for coatings surfaces were made.

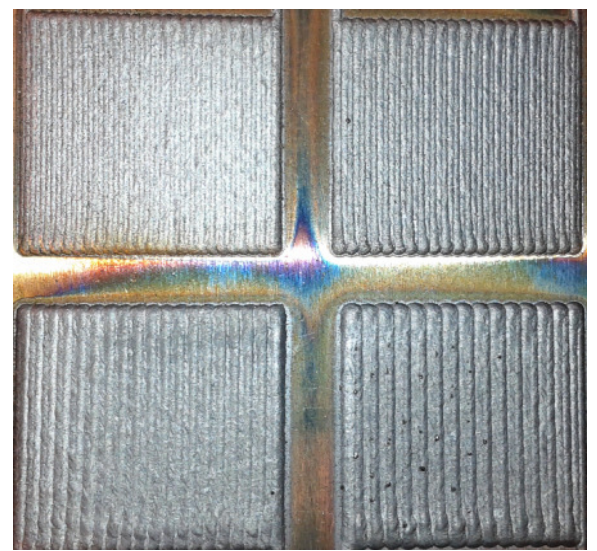

Fig. 2. Experimental sample after laser cladding 
For laser coating surface treatment a flat grinding machine 3B722 was selected. The grinding modes for all coatings were the same: feed $20 \mathrm{~mm} \cdot \mathrm{min}^{-1}$, cutting depth $0,005 \mathrm{~mm}$, rotational speed of $1,400 \mathrm{~min}^{-1}$, grinding wheel $400 \times 63 \times 203-25 \mathrm{~A} 40 \mathrm{~K} 6 \mathrm{~V}$.

For the first sample series the grinding direction was perpendicular to the laser cladded beads and for the second sample series - parallel to them.

The sample flat grinded surface is shown in Fig. 3. After a visual assessment, it was found that all flat grinded surfaces have uniformly expressed the processing trace direction. In turn, to check whether there are differences in surface roughness parameters additional experiments were made.

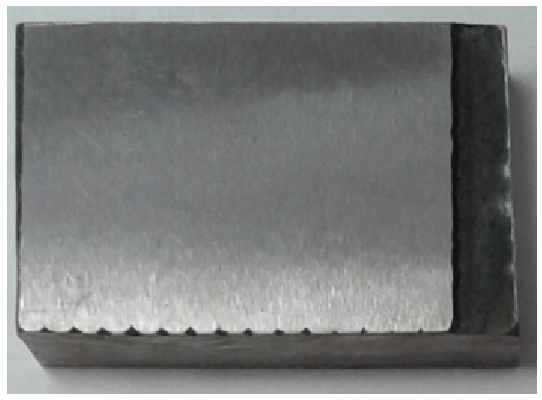

Fig. 3. Experimental sample after flat grinding

In order to make precise surface roughness measurement experiments it is necessary to define specific data that must be entered into measuring software program; these are the evaluation length and the number of measurement points. For this purpose, the parameter $R a$ was measured and on the basis of its value the base length (from the standard ISO 4288) [3] was defined. The input data required for surface roughness measurement experiment are shown in Table 2.

Table 2

Input data for roughness measurement experiment

\begin{tabular}{|c|c|c|c|}
\hline $\begin{array}{c}\text { Sample } \\
\text { No. }\end{array}$ & $\begin{array}{c}\text { Sample length, } \\
\mathbf{m m}\end{array}$ & $\begin{array}{c}\text { Evaluation area, } \\
\mathbf{m m} \mathbf{~} \mathbf{~ m m}\end{array}$ & Number of points \\
\hline No.1-PP - No.8-PP & 0.8 & $3.2 \times 3.2$ & 150 \\
\hline No.1-PL - No.8-PL & 0.8 & $3.2 \times 3.2$ & 150 \\
\hline
\end{tabular}

\section{Results and discussion}

After the measuring experiment, the obtained data processing was carried out [4]. This process consisted of initial surface topography levelling, form and waviness removal. After surface texture filtration 3D roughness parameters and additional 2D parameters for individual surface sections perpendicular and parallel to the processing traces were defined. The surface roughness topographies for some samples are shown in Fig.4.
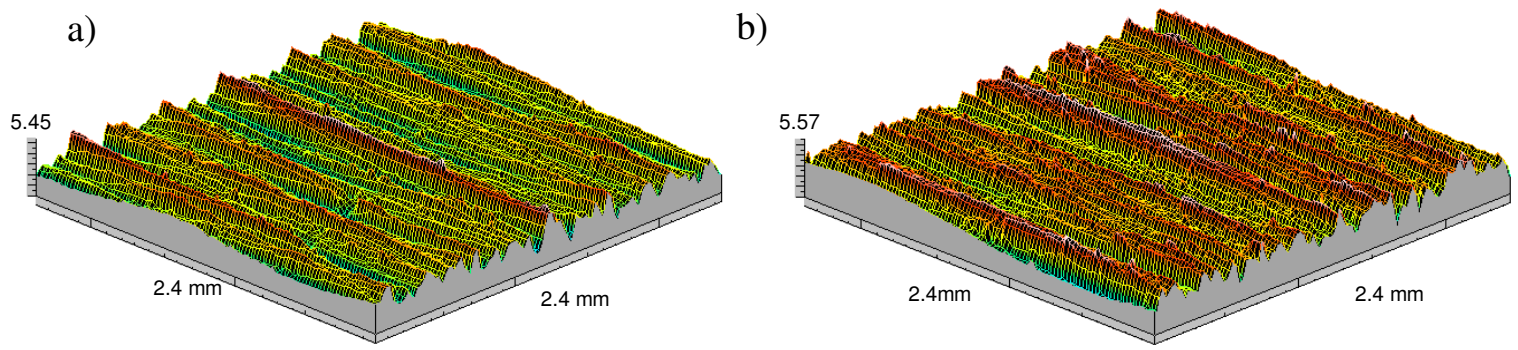

Fig. 4. Surface roughness topography: a - for surface, treated perpendicular to cladded beads; $\mathrm{b}$ - for surface, treated parallel to cladded beads

To find differences between the surface roughness parameters tables with summarized data were prepared (Tables 3 and 4). These two tables contain information about different 3D roughness parameters from the Standard ISO 25178-2 [5] and the mean spacing of profile irregularities $R S m_{1}$ from the Standard ISO 4287. 
Table 3

Surface roughness parameters for samples, grinded perpendicular to cladded beads

\begin{tabular}{|c|c|c|c|c|c|c|c|c|c|}
\hline P-rs & 1-PP & 2-PP & 3-PP & 4-PP & 5-PP & 6-PP & 7-PP & 8-PP & Unit \\
\hline$S a$ & 0.487 & 0.631 & 0.606 & 0.505 & 0.64 & 0.671 & 0.607 & 0.721 & $\mu m$ \\
\hline$S s k$ & -0.604 & -0.279 & -0.384 & -0.226 & 0.109 & -0.064 & -0.369 & -0.0356 & - \\
\hline$S k u$ & 3.63 & 2.82 & 3.28 & 3.39 & 2.71 & 2.82 & 3.83 & 3.02 & - \\
\hline$S t r$ & 0.0414 & 0.0424 & 0.0465 & 0.0434 & 0.0224 & 0.0204 & 0.0204 & 0.0245 & - \\
\hline$S a l$ & 0.0373 & 0.0389 & 0.0390 & 0.0391 & 0.0201 & 0.0195 & 0.0195 & 0.0189 & $\mathrm{~mm}$ \\
\hline$V v$ & 0.0015 & 0.0019 & 0.0021 & 0.0021 & 0.0022 & 0.0024 & 0.0021 & 0.00279 & $\mathrm{~mm}^{3} \cdot \mathrm{mm}^{-2}$ \\
\hline$V m$ & 0.0027 & 0.0033 & 0.0030 & 0.0025 & 0.0024 & 0.0025 & 0.0036 & 0.00336 & $\mathrm{~mm}^{3} \cdot \mathrm{mm}^{-2}$ \\
\hline$R S m_{1}$ & 0.125 & 0.148 & 0.137 & 0.142 & 0.184 & 0.114 & 0.123 & 0.129 & $\mathrm{~mm}^{3} \cdot \mathrm{mm}^{-2}$ \\
\hline
\end{tabular}

Table 4

Surface roughness parameters for samples, grinded parallel to cladded beads

\begin{tabular}{|c|c|c|c|c|c|c|c|c|c|}
\hline P-rs & 1-PL & 2-PL & 3-PL & 4-PL & 5-PL & 6-PL & 7-PL & 8-PL & Unit \\
\hline$S a$ & 0.537 & 0.564 & 0.52 & 0.503 & 0.624 & 0.528 & 0.573 & 0.567 & $\mu \mathrm{m}$ \\
\hline$S s k$ & -0.0664 & -0.161 & -0.251 & -0.268 & -0.381 & 0.0156 & -0.318 & -0.0879 & - \\
\hline$S k u$ & 3.08 & 3.29 & 3.53 & 3.33 & 3.34 & 2.57 & 3.32 & 2.80 & - \\
\hline$S t r$ & 0.0195 & 0.0218 & 0.0266 & 0.0196 & 0.0358 & 0.0377 & 0.0400 & 0.0346 & - \\
\hline$S a l$ & 0.0165 & 0.0195 & 0.0203 & 0.0195 & 0.0390 & 0.0391 & 0.0391 & 0.0391 & $\mathrm{~mm}$ \\
\hline$V v$ & 0.0022 & 0.0022 & 0.0021 & 0.0022 & 0.0024 & 0.0017 & 0.0019 & 0.0022 & $\mathrm{~mm}^{3} \cdot \mathrm{mm}^{-2}$ \\
\hline$V m$ & 0.0022 & 0.0028 & 0.0027 & 0.0027 & 0.0033 & 0.0018 & 0.0028 & 0.0021 & $\mathrm{~mm}^{3} \cdot \mathrm{mm}^{-2}$ \\
\hline$R S m_{1}$ & 0.126 & 0.150 & 0.149 & 0.145 & 0.130 & 0.143 & 0.120 & 0.160 & $\mathrm{~mm}^{3} \cdot \mathrm{mm}^{-2}$ \\
\hline
\end{tabular}

The parameter $\mathrm{Sa}$ is the most useable parameter for roughness characterization, which determines the surface arithmetic mean height. In turn, it is quite difficult to determine the surface roughness peculiarities using this parameter, because it may happen that two surfaces with the same $S a$ values will have different location and shape of microirregularities. Therefore, in addition for characterization of skewness and kurtosis of the surface roughness ordinate distribution function, the roughness parameters $S s k$ and $S k u$ were selected. In general, surfaces with irregular roughness are characterized by the normal (Gaussian) ordinate distribution law, where $99.7 \%$ of all ordinates are grouped around a central axis and the ordinates mean value coincides with the function center [6]. The parameter Ssk value must be equal to 0 and $S k u$ value to 3 . In Tables 3 and 4 it can be seen that for all samples the values of these parameters are close to normal, but there are deviations, which lie outside the permitted $\pm 10 \%$.

Another important parameter for flat grinded surface characterization is the correlation length Sal, which determines how fast link between two points of the surface is descending moving them away from each other. For surfaces with irregular roughness this link disappears very quickly, so the surface roughness correlation function also descends quickly. Only, depending on the mean spacing of the profile elements, the correlation function may descend monotonically or with damped oscillations. Fig. 6 represents the correlation function of the flat grinded surface, which for all other sample surfaces is the same.

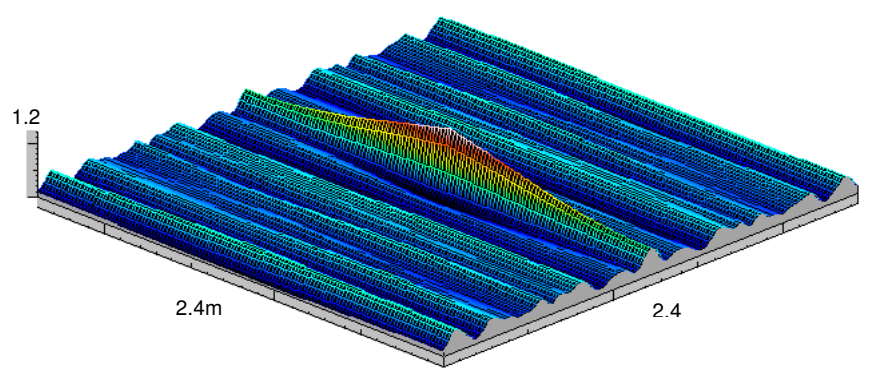

Fig. 6. Correlation function of flat grinded surface 
So, the surface correlation function depends on mean spacing of the profile elements $R S m 1$ and $R S m 2$ in two mutually perpendicular directions. Flat grinded surfaces have expressed processing traces, due to this in directions parallel and perpendicular to the processing traces mean spacing of surface roughness will be different, what can be expressed by the anisotropy coefficient $c$. But in this case, calculations of anisotropy coefficient $c$ are not possible, because considering the literature [7] data the roughness step values in the longitudinal direction are not reliable, due to the profile's mean line and surface's mean plane divergence. So, it was proved [8] that we can use the texture aspect ratio $S t r$, which shows the relationship between the surface steps $\left(R S m_{1}\right.$ and $\left.R S m_{2}\right)$ in the $X$ and $Y$ directions.

In addition, the surface void volume $(V v)$ and material volume $(V m)$ at level of $0.1 \%$ from the highest peak were analysed. In general, the $V v(p)$ and $V m(p)$ parameter groups help predict the void volume for lubrication, as well as the material wear rate and surface area for contacting. These parameters depend on the surface roughness average height $S a$, step parameters $R S m 1$ and $R S m 2$.

According to Tables 3 and 4 it can be concluded that for the samples, which were processed parallel and perpendicular to the cladded beads, the roughness values are very close; it refers to individual sample series and comparing the two series of samples with each other. However, the previously viewed parameter values for each sample series were compared graphically and also using the linear regression equations to determine whether there are correlations between the laser cladding regimes and surface roughness.

The linear regression analysis included the calculations of the coefficient of determination $R^{2}$, Fisher criterion ( $F$-value) and the degree of influence of each process parameter (variable $X$ ) on particular roughness parameters (variable $Y$ ). Table 5 represents general quality of the regression model: the coefficient of determination, which shows the degree of accuracy of process description by the regression model, the model authenticity by the $F$-value, which must be greater than the critical Fisher criterion within a given confidence level $95 \%$. This relation is expressed by significance $F$. The weight of the variable $X$ is checked by the $P$-value, if the value is larger than 0.05 , this indicates that the model term is statistically insignificant.

This means that the relevant independent variable $X$ does not affect the dependent variable $Y$ and the coefficient can be removed from the model. If the value is less than 0.05 , then it can be assumed that the parameter is significant [9].

Table 5 summarizes the roughness parameters for each sample series with included statistical analysis of the regression model.

During the regression analysis, it was found that the significance of relationships was discovered only for three roughness parameters Sal - correlation length, Str - texture aspect ratio and Vvmaterial void volume, where the coefficient of determination for these parameters, depending on the sample series, was greater than 0.82 . The significance $\mathrm{F}$ for the parameter $V v$ (in the perpendicular direction) is 0.056 , what indicates that the model could be accepted within the confidence level of $94 \%$. In turn, for the parameters Sal and Str (in parallel and perpendicular directions) the F-values were very high, which pointed to the fact that the regression models of these parameters are significant within the given probability level.

It was important to determine the significance level of each variable $X$ in order to understand which of the laser cladding parameters had the strongest influence on the roughness parameters values. According to Table 5 data it can be concluded that only the laser beam focus distance as an independent term presented significance, however, other laser cladding parameters were not important at creation of the regression model.

In addition, it is important to note that the model coefficient value indicates the manner, in which a given laser cladding regime will affect the roughness parameter. For example, in parallel direction, the regression model focus coefficients are positive (with a plus sign), what indicates that the parameters Str and Sal values will increase by increase of the focus distance. By contrast, in the perpendicular direction, the focus coefficient is negative, what indicates that the Str and Sal values will decrease by increase of the focal length. The given relationships are clearly visible in Fig. 7 and 8 . 
Regression components for surface roughness parameters

Table 5

\begin{tabular}{|c|c|c|c|c|c|c|c|c|c|}
\hline \multicolumn{10}{|c|}{ Parallel direction } \\
\hline$Y$ & $R^{2}$ & $F$ & Signif. $F$ & $\begin{array}{l}\left(X_{1}\right) \text { OR- } \\
\text { coef. }\end{array}$ & $p$-value & $\begin{array}{l}\left(X_{2}\right) V- \\
\text { coef. }\end{array}$ & $\begin{array}{c}p- \\
\text { value }\end{array}$ & $\begin{array}{l}\left(X_{3}\right) \text { Focus- } \\
\text { coef. }\end{array}$ & $p$-value \\
\hline$S a$ & 0.548 & 1.615 & 0.320 & 0.002 & 0.393 & 2.250 & 0.402 & 0.011 & 0.155 \\
\hline Ssk & 0.358 & 0.742 & 0.580 & -0.009 & 0.278 & 8.303 & 0.464 & -0.002 & 0.955 \\
\hline Sku & 0.615 & 2.134 & 0.239 & 0.021 & 0.162 & -17.50 & 0.402 & -0.075 & 0.183 \\
\hline Str & 0.927 & 17.039 & 0.010 & 0.000 & 0.394 & -0.150 & 0.524 & 0.004 & 0.002 \\
\hline Sal & 0.993 & 184.41 & $9.6 \cdot 10^{-5}$ & $-3.8 \cdot 10^{-5}$ & 0.539 & -0.098 & 0.319 & 0.005 & $1.9 \cdot 10^{-5}$ \\
\hline$V v$ & 0.145 & 0.225 & 0.874 & $4.5 \cdot 10^{-6}$ & 0.748 & 0.003 & 0.876 & $-3.6 \cdot 10^{-5}$ & 0.507 \\
\hline$V m$ & 0.473 & 0.385 & 0.770 & $2.6 \cdot 10^{-5}$ & 0.356 & -0.006 & 0.883 & $-0.2 \cdot 10^{-4}$ & 0.845 \\
\hline$R S m_{1}$ & 0.598 & 1.979 & 0.259 & -0.001 & 0.088 & -0.633 & 0.477 & -0.001 & 0.633 \\
\hline \multicolumn{10}{|c|}{ Perpendicular direction } \\
\hline$Y$ & $R^{2}$ & $\boldsymbol{F}$ & Signif. $F$ & $\begin{array}{l}\left(X_{1}\right) \text { OR- } \\
\text { coef. }\end{array}$ & $p$-value & $\begin{array}{l}\left(X_{2}\right) V- \\
\text { coef. }\end{array}$ & $\begin{array}{c}p- \\
\text { value }\end{array}$ & $\begin{array}{l}\left(X_{3}\right) \text { Focus- } \\
\text { coef. }\end{array}$ & $p$-value \\
\hline$S a$ & 0.584 & 1.874 & 0.275 & -0.003 & 0.379 & -0.250 & 0.961 & 0.026 & 0.097 \\
\hline Ssk & 0.591 & 1.926 & 0.267 & -0.011 & 0.305 & 4.400 & 0.764 & 0.071 & 0.107 \\
\hline Sku & 0.515 & 1.416 & 0.362 & 0.023 & 0.262 & -38.50 & 0.224 & -0.046 & 0.528 \\
\hline Str & 0.981 & 70.235 & $6.4 \cdot 10^{-4}$ & 0 & 1.000 & -0.205 & 0.240 & -0.005 & $1.3 \cdot 10^{-4}$ \\
\hline Sal & 0.996 & 344.72 & $2.7 \cdot 10^{-5}$ & $-8.3 \cdot 10^{-6}$ & 0.843 & -0.018 & 0.783 & -0.005 & $5.6 \cdot 10^{-6}$ \\
\hline$V v$ & 0.822 & 6.170 & 0.056 & $-1.8 \cdot 10^{-6}$ & 0.118 & -0.027 & 0.129 & 0.000 & 0.030 \\
\hline$V m$ & 0.430 & 0.302 & 0.823 & $1.0 \cdot 10^{-6}$ & 0.971 & -0.037 & 0.401 & $1.5 \cdot 10^{-5}$ & 0.884 \\
\hline$R S m_{1}$ & 0.108 & 0.161 & 0.917 & 0.001 & 0.666 & 0.992 & 0.632 & 0.000 & 0.977 \\
\hline
\end{tabular}

Changes in Sal values will affect the decreasing intensity of the surface correlation function. This means that at low Sal values the link between the surface points will be lost faster and it will be quite difficult to predict the height of the $Z$ coordinate at a distance $X$ from the starting point. As it was mentioned above, the correlation length depends on the mean spacing of the profile elements. At a lower roughness step, the $S a l$ values will also be smaller.

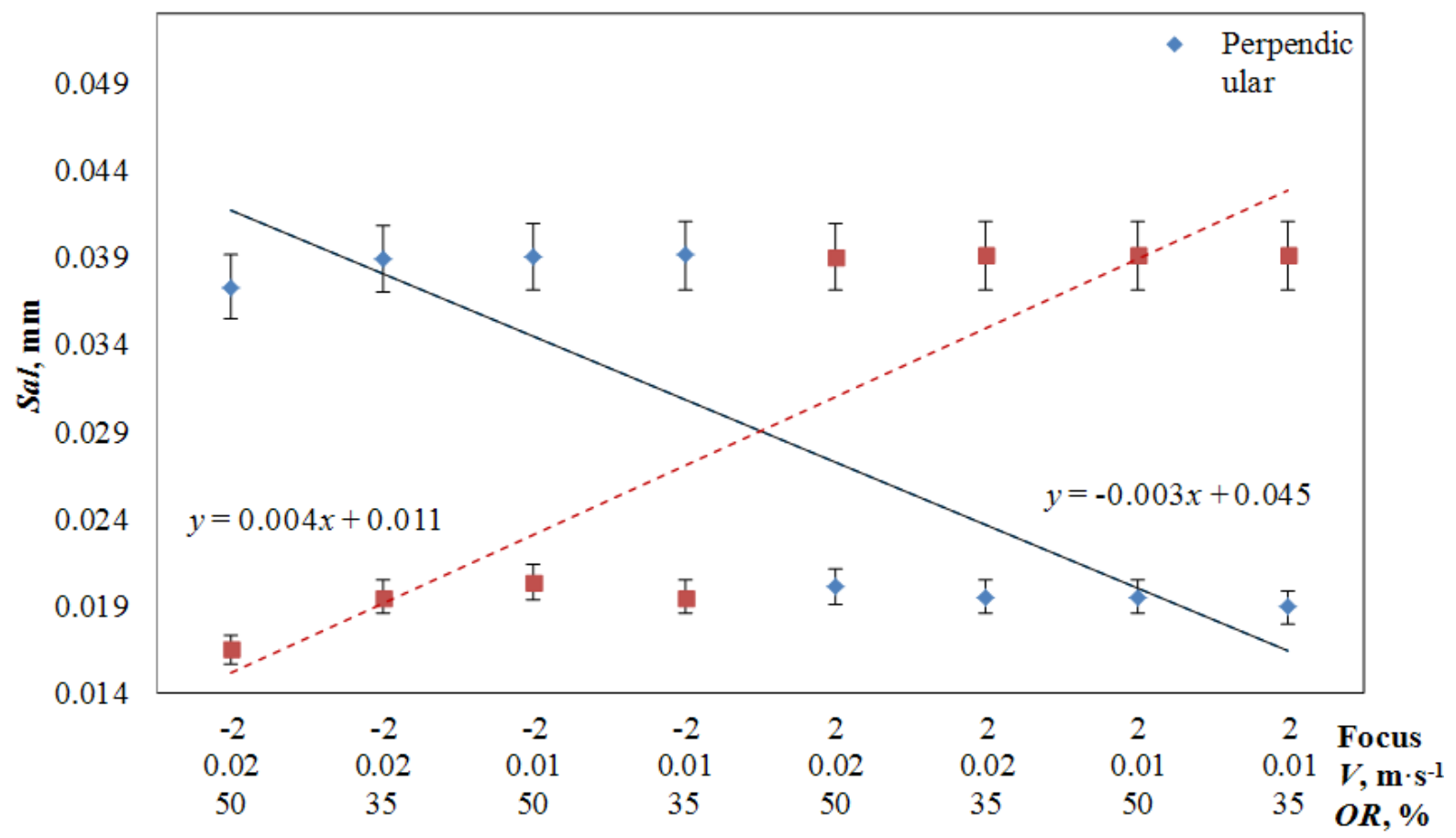

Fig. 7. Relationship between values of parameter $\mathrm{Sal}$ for both sample series 


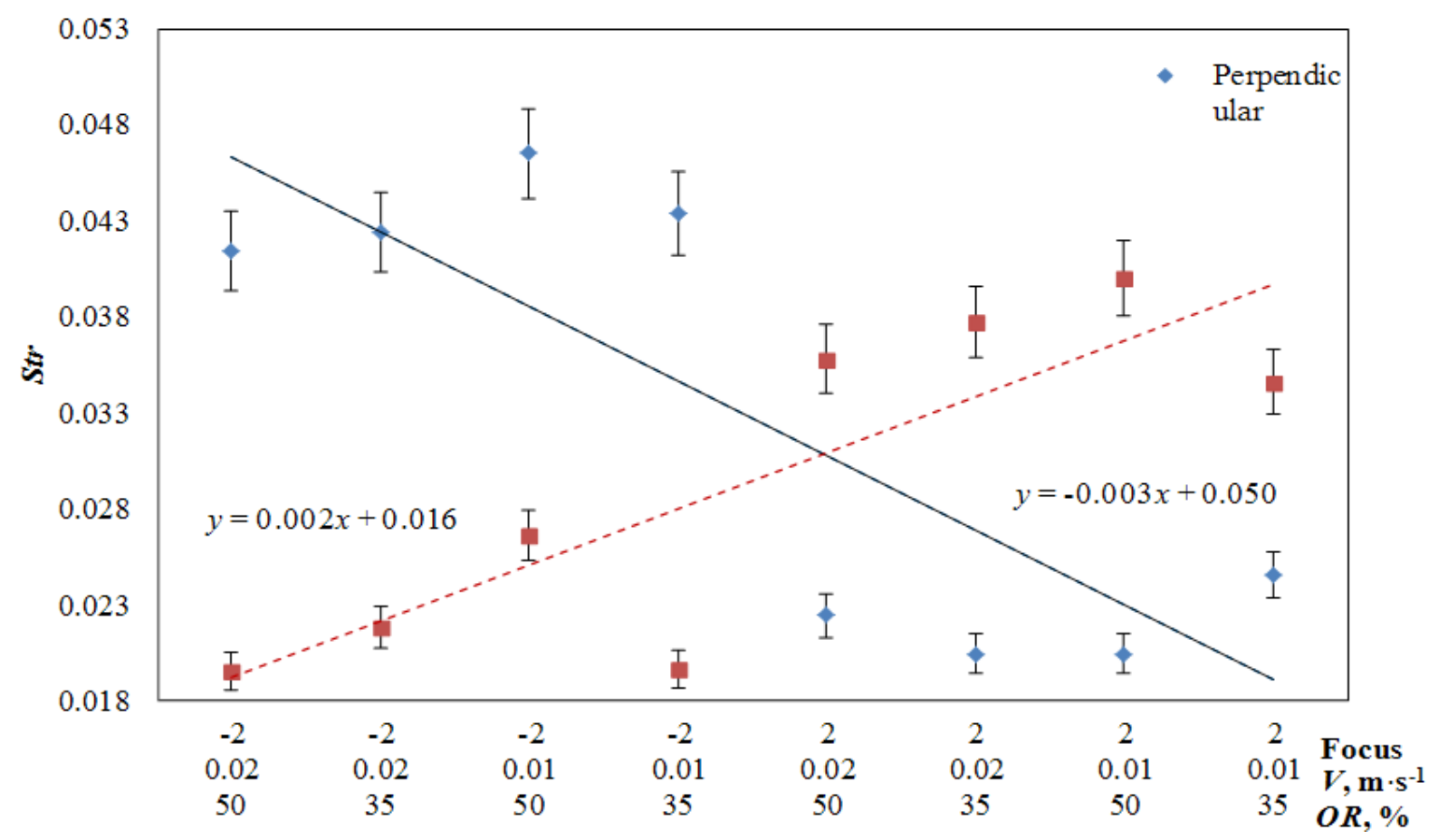

Fig. 8. Relationship between values of parameter Str for both sample series

With the texture aspect ratio Str changing, the relation between the surface roughness steps in two mutually perpendicular directions also will be changed. The smaller the values of Str, the greater the roughness anisotropy will be. In turn, to determine how seriously the Sal and Str values may be affected by changing the focal length, it is necessary to make additional experiments.

\section{Conclusions}

The high-speed tool steel coatings were created, with the aim to investigate the influence of the laser cladding process parameters, namely: overlap ratio of laser cladding tracks, scanning speed and laser beam focus displacement, and in addition, the influence of the mechanical grinding directions. The produced coatings were evaluated by testing of surface roughness after post-processing. The obtained results were also statistically analysed.

1. The surface ordinate distribution function, its excess and kurtosis values for all investigated samples conform to the normal Gaussian distribution law.

2. The regression model is applicable only for two roughness parameters: Str - texture aspect ratio and $\mathrm{Sal}$ - correlation length.

3. The parameters Str and Sal values are affected only by the focus length, influence of overlap ratio and the movement speed of the laser head is negligible.

4. With the increase of the focus, the Str and Sal values also will be increased for samples processed parallel to the cladded beads, in turn, in the direction perpendicular to the cladded beads - the Str and $S a l$ values will decrease.

5. The main roughness parameters for both sample series did not differ essentially, pointing to the fact that direction of mechanical treatment towards the direction of laser cladding does not affect surface roughness, what also indicates the isotropy of the coatings properties.

\section{References}

1. Иванов А.В., Пирозерская О.Л. Перспективные способы наплавки и механической обработки восстанавливаемых деталей (Perspective ways of cladding and machining of recoverable parts). Технико-технологические проблемы сервиса: Диагностика и ремонт, 2010, No 13, (In Russian).

2. Rombouts M., Maes G., Hendrix W., Delarbre E., Motmans F. Surface finish after laser metal deposition. Proceedings of International conference "Lasers in Manufacturing 2013", May 13-16, 2013, Munich, Germany, pp. 803-807. 
3. LVS EN ISO 4288 standard "Geometrical Product Specifications (GPS) - Surface texture: Profile method - Rules and procedures for the assessment of surface texture".

4. Exploring Surface Texture, 7th edition. Great Britain: Taylor Hobson Limited, 2011, 110 p., [online] [01.03.2016], Available at: http://www.taylor-hobson.com/uploads/learningzone/ metrology-books/Exploring \%20Surface \%20Texture \%202014.pdf.

5. LVS EN ISO 25178-2 standard "Geometrical product specifications (GPS) - Surface texture: Areal - Part 2: Terms, definitions and surface texture parameters".

6. Рудзитис Я.А. Контактная механика поверхностей. Часть 1. (Mechanics of surface contact. Part 1). Riga: Riga Technical University, 2007. 193 p. (in Russian).

7. Bulaha N., Rudzitis J., Lungevics J., Linins O., Berzins K. Analysis and calculation of spacing parameters of anisotropic 3D surface roughness. Latvian journal of physics and technical sciences, vol.54, 2017, (In Press).

8. Bulaha N., Rudzitis J., Lungevics J., Linins O., Krizbergs J.. Research of surface roughness anisotropy Latvian journal of physics and technical sciences, vol.54, 2017, (In Press).

9. Auzins J., Janusevskis A. Eksperimentu plānošana un analīze (Planning and analysis of experiments). Riga: RTU, 2007, 255 p. (in Latvian). 